\title{
Warwickshire consultants' 'Training the trainers' course
}

\author{
Andrew Whitehouse
}

\begin{abstract}
Summary
To train junior hospital doctors more quickly and effectively as envisaged by the Calman reforms, consultants will need to develop their adult education skills. This paper describes a course set up and attended by a mixed group of Warwickshire consultants to improve their understanding of these skills. The course organisation and content is described and the 'learner-centred education' model, educational supervision techniques, giving feedback on performance, goal setting, learning contracts and other topics covered are explained. A 12-month interval questionnaire evaluation by attendants shows that the principles taught in the course were being widely applied a year later. Thus, at a modest cost, consultants can receive a valuable basic training in adult education.
\end{abstract}

Keywords: education, training course

The Calman reforms of specialist training, combined with the New Deal, will mean that junior doctor training must become shorter and more effective. This means that consultant trainers will need to be better educators, for which task most are unprepared. They will have to be taught how to teach.

In 1993, a small group of Warwickshire consultants decided to set up a structured course for themselves and colleagues designed to improve their teaching skills. The regional postgraduate dean provided funding. A six-day course consisting of three two-day sessions in January, April and July 1994 was arranged in a local hotel.

We recruited four key course facilitators and advisers. Two were GPs with long training experience and two were academic educationalists with private sector experience of personnel development and trainee management. Clinical tutors from all Warwickshire hospitals were asked for suitable volunteer nominees. Twenty-four consultants from a wide range of specialties from six different hospitals in Warwickshire were accepted on the course. Chief Executives gave special leave.

George Eliot Hospital, College Street, Nuneaton, Warwickshire CV10 7DJ, UK A Whitehouse

The course was based on the principle of learner-centred education: that adults must identify their own educational goals and be individually responsible for their attainment. The role of the teacher in this is to act as a 'coach' or adviser to the learner rather than simply as purveyor of information. ${ }^{1}$ This changes the traditional teacher/pupil relationship from an authoritarian one to one of partnership in which the adult learner may more comfortably define his needs and arrange to develop himself in the most appropriate way. Throughout the course the facilitators used this method to convey its value.

Specific topics considered were:

\section{THE EXPERIENTIAL LEARNING CYCLE}

This model expects the learner firstly to define his learning goal specifically (eg, to perform a good cholecystectomy) ${ }^{2} \mathrm{He}$ then must prepare the learning exercise (reading, watching a video, assisting at surgery) and then perform under supervision. He will then reflect on that experience (reviewing the outcome, discussing with his trainer). Finally, he will generalise from that learning to other situations, thus widening the value of what has been learnt (figure).

The deliberate breakdown of this process into components encourages concentration on each phase. The itemisation of learning goals helps to avoid omissions and the 'reflect' phase encourages critical self-appraisal which may not otherwise take place.

\section{THE 'LEARNING STYLES' EXERCISE}

Honey and Mumford recognised that individuals have different preferred learning styles and broke these down into 'activist', 'theorist', 'reflector' and 'pragmatist'. ${ }^{3}$ A questionnaire, validated by wide application, allows definition of one's preferred approach. It can be helpful to known one's pupil's learning style in order to advise him and also to provide the most suitable learning environment for him. Our course allowed each attendant to establish his or her own learning style.

\section{OPTIMUM LEARNING ENVIRONMENTS}

Effective learning is likeliest to occur in a nonthreatening situation in which the learner feels

\section{Course content}

Figure The experiential learning cycle 
comfortable to acknowledge ignorance, is encouraged personally to contribute to the session, is motivated by appropriate praise, is not penalised for being 'wrong', feels relaxed and free from interruption ('protected time') and, above all, finds the session enjoyable and fun. Throughout the course these truths were amply demonstrated. A small body of opinion had preferred the 'hard knocks' school of teaching, but moderated this view with experience during the course.

\section{SUPERVISION AND COUNSELLING}

If the role of a teacher of adults is primarily to help the learner to identify and realise learning goals then the educational supervisor's role is fundamental. This supervisor role does not come naturally to all consultants and certain principles are helpful. Some of these were suggested to us and practised in small group formats (a structure of small groups of six, each with a facilitator, allowing easy breakdown into two trios, was used throughout the course).

Educational supervisions should be planned in advance and take place uninterrupted in a private room. The supervisor should be ready to listen to the trainee's concerns primarily and to guide rather than instruct. An atmosphere of mutual trust is essential. The trainee must be encouraged to set himself goals for the forthcoming period. Criteria for appraisal need to be agreed early and written documentation should be kept. A follow-up meeting must be planned at the end of the session.

The notion of goal-setting within supervisions was dealt with. These may be either simple goals (eg, learn cardiopulmonary resuscitation) or more complex goals (eg, to decide which branch of medicine to pursue). Again, the learner-centred principle is the key. The trainee must be drawn into the moment at which he recognises and defines what his goals are. This can be done in a structured way during supervision by making the trainee identify, step by step, each goal, its implications, the resources needed to achieve it and his timetable for the tasks. The trainee must always carry the responsibility.

\section{THE 'FORMAL TEACHING SESSION'}

Formal lectures will remain important in medical education. How often, however, poor technique or 'process' interferes with the transfer of information or 'content'. The ideal formal lecture was anatomised in one session. In another, within small groups, each member gave a talk for 15 minutes on a topic (nonmedical) of their choice, following the brief to use unfamiliar teaching styles or methods. This session was enormously popular. It allowed individuals, within a light-hearted, unthreatening and supportive atmosphere, to try out manoeuvres they had not used before. The speakers changed the layout of the room, used unexpected visual aids, varied the style within a session, involved the audience, and used drama and suspense to maintain interest. These new insights into the possible variety of 'process' in running an educational session caused much interest and excitement.
GIVING FEEDBACK ON PERFORMANCE

We often fail to do this. Sometimes it feels uncomfortable, and it can be demotivating to criticise and draw attention to shortcomings. A system which is both comfortable for the teacher and motivating for the learner and yet allows for attention to be drawn to shortcomings is optimal. Such a method was devised by Pendleton, ${ }^{5}$ who defined a set of rules for the purpose. First, the learner is asked to comment on aspects of the item (eg, an operation just performed, management of a clinical problem or a full take day completed, a 'bad news giving' session) that he performed well. In other words, he is asked to compliment himself. $\mathrm{He}$ is then asked to comment on the aspects that could have gone better, and how. The teacher then goes through the same process - first, the congratulations for the praiseworthy aspects (and there is always something), then the advice designed to assist improvement. The teacher then finishes with a further positive remark on some aspect of the pupil's performance. This simple formula has the strength of being schematic and formal, which reduces embarrassment. It promotes discussion of shortcomings within a reassuring atmosphere. Nothing motivates like a compliment. How often do most trainers frankly compliment their trainees? How much more comfortable it would feel to correct them if they were also used to being praised.

\section{THE LEARNING CONTRACT}

The training function of a post can be made explicit in a learning contract. This is agreed between trainer and trainee at the beginning of an attachment. It will specify the (jointly established) educational objectives of the forthcoming period, the provisions available to support these objectives and also a description and explanation of the appraisals planned. The document will specify what is expected of the trainee and of the trainer in the achievement of learning objectives. It will also serve as a focus for early discussion about education within the post.

\section{USE OF VIDEO IN TEACHING}

A GP regional associate adviser in postgraduate education demonstrated video monitoring of an educational supervision with a trainee. This use of video allows a teacher to improve his counselling skills. Video recording of a trainee in consultation with a patient was also used to demonstrate the opportunity this offers the trainee to review and upgrade his consultation skills. Informed consent by the patient is needed. A third use of video was recognised by consultants on the course, two of whom, as intermodule homework, made video recordings of themselves teaching practical skills (carpal tunnel release and liver biopsy). Such records may be helpful revision for the trainee preparing for a procedure of this type.

\section{SMALL GROUP ACTIVITIES}

Teaching and learning in hospitals often occurs within a small group of doctors. A ward round is such a group, so is a session in which a 
consultant or registrar tackles a topic with a group of medical students. Such a setting provides a rich opportunity for information exchange and for trainees to recognise further training needs. A group leader can make best use of the occasion by applying basic knowledge of group dynamics. One should recognise a distinction between group task (content) and group maintenance (process). ${ }^{4,6}$ Each member should be brought into the discussion. None should be allowed to dominate. The behaviour of group members may be constructive or destructive to the goal of learning and the leader may, with perception, use his position to optimise outcome, ie, enhance learning. We tend to concentrate on content in such situations and to neglect process. In fact, the medium is the message, the process is fundamental.

\section{Outcomes and evaluations}

As the course progressed module by module it was interesting to see how individuals brought back to groups their own reworkings of themes considered. Specific homework projects were set. Some doctors made videos of teaching a practical skill. Some produced a skeleton learning contract. For many, the experience was valuable as an opportunity to meet with other consultants from around the county in a congenial atmosphere, to talk about postgraduate education issues informally. Some of the attending consultants, however, clearly felt, initially, uncomfortable with the course format. More used to a conventional teacher/pupil style, as most of us are, the learner-centred model can be challenging, even threatening. Some also felt that some of the course content was either obvious or arcane. It was clear, however, both from observation and from the final evaluations of the course, that a majority of the consultants were gradually introducing into their practice a number of the principles demonstrated. These evaluations mentioned most frequently the 'challenge to assumptions' it had given and the opportunity to review practice in a nonthreatening environment. All the consultants valued the exposure to others' teaching techniques and saw the course as a first step to a new approach they would develop further. Some reported difficulty with certain theoretical concepts and asked for a more didactic approach to introduce new ideas. All reported that they would incorporate at least some new principles into their teaching. Formal written scores by attendants at the close of the course gave an average 7.1 out of 10 rating for value of the course overall and 7.3 out of 10 for relevance and usefulness of the learning to their own teaching practice.

The group resolved to continue meeting to compare notes and teaching activities after the course. Three single day review meetings have since taken place. Topics discussed (all chosen by those present) included trainee assessment, varieties of tutorial, learning contracts and planning half-day training sessions for Senior House Officers. These six monthly meetings continue.

\section{Interval survey of course attendants}

Ten months after the course finished those who attended it were sent a questionnaire designed to establish the extent to which they were using the principles the course had proposed. There were 21 replies from the 24 attendants. Topics covered were listed and briefly summarised. The consultants were asked if they recalled the topic, if they had incorporated it into their practice and if not, why not? If they had found the topic interesting and potentially useful and had only failed to use it in their practice because of insufficient time they were asked to state this.

\section{Results}

It was notable that the majority of topics recalled had either been absorbed into consultants' teaching practice, or would have been, time permitting (table). The findings support two conclusions: that consultants find these principles valuable and that time to bring good adult education practice into hospital training programmes is hard to find. Hospital consultants will not be surprised by the latter finding, overwhelmed as many are by clinical work, administration, audit and other, unfunded, activities. Nonetheless, somehow, if teaching is to improve, NHS Trusts and postgraduate deans will need to support and fund those who train hospital doctors.

\section{Cost}

A budget of $£ 24000$ was provided to fund this course. This covered costs of accommodation

Table Responses to 21 questionnaires sent out 10 months after programme (total sent out=24)

\begin{tabular}{llccl}
\hline Topic & Recall & $\begin{array}{l}\text { Now } \\
\text { use }\end{array}$ & $\begin{array}{l}\text { Helpful but } \\
\text { no time to use }\end{array}$ & Not used \\
\hline Learner-centred education & 19 & 19 & 1 & \\
Experiential learning cycle & 13 & 7 & 6 & 5 (pointless/surgeons all same) \\
Learning styles excercise & 19 & 6 & 8 & 3 (resources/conflict with service) \\
Optimum learning environment & 19 & 15 & 1 & 1 (not enough confidence) \\
Pendleton principles & 18 & 12 & 5 & 3 (on drawing board) \\
Learning contracts & 20 & 10 & 7 & 3 (no expertise/resource) \\
Video & 18 & 5 & 10 & 3 (pointless/no opportunity) \\
Principles for formal teaching sessions & 18 & 18 & & 4 \\
Small groups & 17 & 10 & 4 &
\end{tabular}




\section{Summary points}

- the Calman reforms require consultants to train specialists in a more structured way

- Warwickshire hospital consultants responded enthusiastically to a course providing a basic training in adult educational skills

- the 'learner centred' principle, improved presentation skills, educational supervision and use of video and learning contracts were accepted as valuable in postgraduate training by the consultants

- twelve months later many of these ideas were being used in their teaching by the consultants, although pressure on time and lack of resources often prevented this

and board for all consultants and facilitators (including one night lodging for each of the three modules), honoraria for the teachers, all correspondence, hire of seminar rooms and equipment (videos, visual aids, etc). The cost

1 Knowles $M$. The modern practice of adult education: from pedagogy to androgogy Englewood Cliffs, New Jersey: Cambridge Book Company, 1970 .

2 Kolb DA. Experiential learning. Englewood Cliffs, New Jersey: Prentice Hall, 1984

3 Honey P, Mumford A. The manual of learning styles. 3rd edn. Maidenhead: P Honey, 1992. of the subsequent review days (attended by 12-15 consultants each session) was also covered within this budget. It cost, therefore, approximately $£ 1000$ per consultant to attend the six-day course and follow-up days. This would have been substantially less had the course not been residential.

\section{Conclusions}

We have shown that it is easy to set up a course designed to train consultants as trainers and that consultants value this. If the new arrangements for the training of hospital specialists are to work, the wider practice of good adult educational method will be important. Locally organised courses, on the lines of the Warwickshire course, may be a helpful way of stimulating the interest of consultants in adult education. Regional postgraduate deans can encourage better training by support for such initiatives.

4 Luft J. Group process: an introduction to group dynamics. Palo Alto, California: Mayfield, 1970.

Pendleton $\mathrm{D}$. The consultation, an approach to learning and teaching. Oxford: Oxford University Press, 1984.

6 Kindred M. Once upon a group. 2nd edn. Southwell: $M$ Kindred, 1987.

James Marion Sims (1813-1883) was born in Lancaster, South Carolina, USA, and qualified from Jefferson Medical College in Philadelphia in 1835. He wrote a successful textbook of gynaecology (1866) and devised the Sims speculum, the knee - chest position for gynaecological examination, and a technique for the repair of vesico-vaginal fistulae. After 18 years general practice in Alabama he became a gynaecologist in New York City. In 1870 he helped organise the Anglo-American Ambulance Corps during the FrancoPrussian War. He was surgeon in charge of a military hospital in Sedan. For this participation he received honours from France, Belgium and Spain. He became President of the American Medical Association. A statue of Marion Sims may be found in Bryant Park opposite the New York Academy of Medicine. He died suddenly in New York on 13 November 1883. - DG Fames 